\title{
Some Preliminary Notes on the Subordination of Women ${ }^{1}$
}

\section{Ann Whitehead}

In the report on the Conference published in this Bulletin issue, as in the papers prepared for the Conference by members of the IDS Subordination of Women Workshop, a number of assumptions are made and a somewhat specialised language is used. Both call for some explanation.

Initially the Workshop was set up to develop conceptual tools which would lead to more sophisticated analyses of the impact of social change, whether planned or unplanned, on the position of women in society. These tools were to be tested not only in the work of the Workshops members (most of whom have had experience of policy evaluation in the Third World), but also were to be passed on to people involved in policy making who are associated with the Institute. The Workshop discussions all started from a number of assumptions which are relatively commonly held by feminists, but perhaps less well known in other circles.

Our first assumption was that any study of women and development, of the effects of education, lower fertility rates, changing production, etc., on women's position or on their status, cannot start from the viewpoint that the problem is women, but rather men and women, and more specifically the socially constituted relations between them:

'What is a domesticated woman? A female of the species. . . . She only becomes a domestic, a wife, a chattel, a playboy bunny, a prostitute or a human dictaphone in certain relations. Torn from these relationships, she is no more the help-mate of man than gold in itself is money...' (Rubin 1975: 158).

The rejection of women as an adequate analytical category has gained much wider acceptance since International Women's Year, but there are still plenty of development and other writings which imply that this conceptual clarification has yet to be adopted by many (and perhaps even rejected by some).

\footnotetext{
I These comments should be read as a personal view of the development of aspects of our language which has been built
up from our collective discussions, rather than strictly speaking the product of an individual.
}

Our second assumption was that relations between men and women are socially constituted and not derived from biology. Thus we found it useful to use the term gender relations to distinguish such social relations between men and women from those characteristics which can be derived from biological difference (Oakley 1972, Rubin 1975, Rosaldo \& Lamphere 1974, Edholm et al 1977). Here we have followed a general convention in writings on women which reserves the term sex to refer to characteristics or instincts which can be said to be derived from biology (such as primary or secondary sexual characteristics). In brief, sex is the province of biology while gender is the province of social science. A corollary is that gender relations, as social constructs, are historically specific forms that relations between men and women take in a given society. ${ }^{2}$

Our third assumption was that relations between socially constructed men and women are not necessarily, nor obviously, harmonious and non-conflicting. In the booklet describing the IDS project ${ }^{3}$ we pointed out that, despite all the discussion within the development field on the position of rural and urban women that had taken place during the UN second development decade, there had been little questioning of the assumption that the roles of men and women are complementary. The belief that what men and women do within their own spheres and domains fits together in a fundamentally co-operative fashion, led to the policy position that the benefits of development can be expected to accrue equitably to both genders, even when programmes are directed specifically to males. But the assessments of the impact of social and economic change on the position of women, and of the integration of women into development planning which arose out of International Women's Year showed above all that large sectors of women were losing out. They were benefiting most unequally from development. It actually became fashionable in some circles to attribute the failure of development itself to the failure to involve women in it in a substantial way.

The major explanation offered for the deteriorating position of women, and the non-fulfillment of

\footnotetext{
2 Although we have tried to refine terminology, it is clear that such tried and true terms as the sexual division of labour will continue to be used despite its inaccurate implications will continue to be used despite

3 The Subordination of Women Profect at IDS.
} 
development expectations, was that Western models of development were eurocentric and androcentric. Planners, in addition to exporting models of capital intensive, mechanised and urban biased development, also exported Western models of the proper roles of women, which ignored their different but highly valued roles in other societies, and the strength of the opposition to adopting Western models. The accumulated evidence of the worsening position of women we took as our basis for abandoning the non-conflictual model of gender relations and starting with the contrary one - that the socially constructed relations between the genders may be ones of opposition and conflict. Such conflicts of interest between men and women are not to be analysed as a fact of biology or nature, but as socially determined. Thus the form that they take may be very different in different circumstances. Our position was, then, that collection of data, the piling up of example after example of women's worsening position could no longer advance the study of the effects of development on women of the Third World, and our task was rather to develop a more theoretical approach-an approach which would theorise gender and gender relations. ${ }^{4}$

\section{Relations between men and women}

Gender, gender relations, relations between men and women, are not necessarily familiar ways of referring to something which we all experience. The various forms of gender and gender relations which are described and categorised below make up what for shorthand we refer to as gender relations, and are the substratum (data) to which theory and conceptual tools are applied.

One of the specific forms of oppression which women suffer, and which other oppressed social categories share, is the inability to be in social relationship and social situations in which gender is not present. Our experience as women is of being always perceived and treated as members of a gender category about which there are all kinds of stereotyped beliefs, and which is inferior to the alternative gender category, that of men. This experience is well documented in women's

4 In retrospect it was probably inaccurate to suggest that the work on women hitherto lacked theory. It did not strictly speaking lack theory-it was rather imbued with certain kinds of theory or ideology, rarely made explicit. Indeed a useful exercise for any one unfamiliar with the literature on women and development, but who is familiar with the forms of and development, but who is famillar "with the forms of analysis within their own discipline is "spot the paradigm" That is, going through the literature and recognising in the context of women general paradigms from their own fieldstructuralism; functionalism; maximisation; redistributionthey are all there. Indeed sociologists will already have spotted a strong similarity in the description of the complementary/conflictual models of gender relations with the debate over the consensus/conflict models of class. accounts of their objectification as they walk down the street or meet members of the other, dominant, gender category in leisure-time pursuits where sexual identity is often dominant. But it is not confined to these situations. It is, for example, present in the way men and women behave in the workplace, whether this be the factory floor, the operating theatre or the seminar room. Gender then, like race, is never absent, and ambiguities about gender are more or less poorly tolerated (we worry if we are not sure whether a person we are talking to is a man or a woman).

In addition there are some relationships which may be called, in sociological terms, gender ascriptive. In them, to describe the position is to describe the gender. A good example of this is the position of husband and wife, which presupposes a man and a woman respectively. Indeed the legal definition of marriage involves a union of persons of definite and opposite genders. Many other kinship and family relationships are also gender specific, the terms used to denote them are themselves gender terms-thus mother, father, brother, sister, aunt, uncle, grandmother, grandfather. Those theories and concepts which stress the dominance of relations between men and women have as their model this category-relations in which gender is ascriptive in the relationship.

In emphasising the relations of subordination between men and women who are in conjugal relations and live in households, it must not be implied that these are the only social relations in which gender is significant. Gender is present in another sense in a whole set of activities. There are many situations in which gender is a characteristic, although the relations themselves are not gender relations as defined above. That is to say it is not necessary to be either a man or a woman to do the activity, but empirically, the genders are differentially recruited. A good example in industrial society is the large number of occupations in which gender is not legally a criterion for holding a particular job and earning a particular income, but where in effect there is gender selection. So secretaries statistically are most often female, while their bosses are male. Correspondingly secretaries are usually thought of as female, and bosses are thought of as male. Gender is thus a characteristic of the situation. An additional aspect of the gender characteristic situation is that where there are hierarchical relations in organisations such as the workplace, the gender categories are assigned to places within them so as not to contradict the 'fundamental' hierarchy of men above women which occurs in gender relational situations. 
Gender as a characteristic leads to social domination, i.e. the pervasive widespread social, political and economic power of men as a category over women as a category. This has historically taken the form in Britain of legal and informal boundaries to women entering certain occupations, women's political powerlessness, social invisibility, and so on. The social domination is distinguishable from situations of subordination between men and women in relations which are predicated on the persons occupying them being of specific genders. While it would be quite wrong to characterise the 19th century and early 20th century women's movement as concerned only with social domination, the contemporary women's movement has concenterated on the relational arena of subordination in its political and theoretical discussions of women's oppression in the family.

This way of drawing attention to some of the different forms of experiencing gender is at once sociological, and also fairly non-theoretical. Using sociological language however is not meant to imply use of role-theory models. Although we specify forms of gender we can point as yet to no theory about their basis, nor the links between them. Focusing on them is a necessary starting point, however, for understanding the term subordination.

\section{Why subordination?}

The terms used to refer to the general character of gender relations have clearly changed over time and are subject to disagreement. In common with a number of other people we have chosen the term subordination to refer to the general character of male/female relations. It was one of a number of terms which arose to conceptualise the specificity of male dominance in gender relations as distinct from women's historically specific experience of exploitation, inequality or oppression, and to draw attention to the need to determine that specificity. We use subordination in preference to patriarchy for a number of reasons. Patriarchy, the power of a husband/father over his wives, children and property, is really a specific form of male dominance. Patriarchy tends to refer mainly to the relational aspects of gender, and to imply, if we use the categories above, the individual relations of subordination which are often gender ascriptive. It does not cover all the forms of gender relations. In certain writings its usage tends to suggest an unchanging, historically constant patriarchy, rather than changing forms of dominance, and it is often used in feminist political analysis which gives primacy to the relations of reproduction between men and women.
Here we should highlight the fact that women are in some circumstances exploited, oppressed and unequal, but these are terms which belong to theoretical (and political) analyses which do not deal adequately with gender relations. One could say that gender relations in some circumstances may take the form of the oppression of women by certain categories of men. We would make a distinction between these terms and that of patriarchy.

We use the term subordination then to make the general point that the character of gender relations is that of male dominance and female subordination. The subject matter of analysis must then be the various forms that subordination takes. The work of women in Britain today can be taken to illustrate this. The characteristics of a woman's work as a wage labourer are gender related and she is subordinated in the sense that this is so. She works in specific industries and jobs; earns less than men; if married and a mother she generally works part-time. The relations under which she performs wage labour are class relations of exploitation. In addition, she performs domestic work in the home which is unwaged and which she does by virtue of being a wife and mother. By the same token she may, over her life cycle, also do unwaged domestic work for members of other households to whom she is related by ties of kinship or affinity. The relations under which she performs her primary domestic work are gender relations of subordination.

What this means is that women as a whole have less control over the family's economic resources; they also have less status relative to that of their husbands in that a greater share of decision making and authority goes to men; relations between husbands and wives are marked by the behavioural components of inferiority/superiority, deference, and so on. By and large the family based household is a hierarchical structure marked by the dependency of wives and children on the husband, whose specific role in the household is marked by the bureaucratic definition of him as its head.

While we can describe the multiplicity of forms of subordination even within one social situation it is another matter to draw links between them. At the same time in another social situation, say for example that of women in the rural areas of Third World countries, the forms of subordination and links between them may be very different.

It is to the difficult task of analysing the forms and the links between them that we must now address ourselves. What are the links between 
economic relations between people, whether members of a household or of different social classes, and relations of subordination between the genders? How do changing economic relations affect gender relations? To what new forms of gender relations do changes in productive relations give rise? Does the motor for change in gender relations always come from changing economic relations? In restructuring gender relations what is the role played by changing conditions of reproduction of labour?

It is to some of these questions that the Conference addressed itself.

\section{References}

Edholm, F., O. Harris and K. Young, 1977, Conceptualising Women, Critique of Anthropology No. $9 / 10$

Oakley, A., 1972, Sex, Gender and Society, Maurice Temple Smith, London

Rosaldo, M., V. L. Lamphere (eds.), 1974, Culture and Society, Stanford University Press, Stanford

Rubin, G., 1978, The Traffic in Women, in $\mathbf{R}$. Reiter (ed.), Towards an Anthropology of Women, Monthly Review Press, New York 